\title{
Pregnancy outcome in patient who had first trimester bleeding in previous pregnancy: a prospective study
}

\author{
Faswila M., Ramya N. R.*
}

Department of Obstetrics and Gynecology, Yenepoya Medical College, Mangalore, Karnataka, India

Received: 13 January 2020

Accepted: 05 February 2020

*Correspondence:

Dr. Ramya N. R.,

E-mail: dr.ramya136@gmail.com

Copyright: (C) the author(s), publisher and licensee Medip Academy. This is an open-access article distributed under the terms of the Creative Commons Attribution Non-Commercial License, which permits unrestricted non-commercial use, distribution, and reproduction in any medium, provided the original work is properly cited.

\begin{abstract}
Background: Patient who had history of spontaneous abortion in her previous pregnancy is associated with adverse outcome in her present pregnancy.

Methods: A total 63 pregnant women attending OPD and admitted in department of obstetrics and gynecology, Yenepoya Medical College, from April 2017 to September 2017, considered and outcome were studied.

Results: Out of 63 patient's majority $(57.1 \%)$ of patients belong to the age group 21-29 year. Anemia was found to be very severe in $4.3 \%$, severe in $10 \%$ and moderate in $30 \%$ patients. Maximum patients $(45.7 \%)$ were with history of previous one abortion followed by previous two abortions (38.6\%). The final outcomes were term livebirth 47 (74.3\%), abortion $9(14.3 \%)$, preterm delivery $5(8.6 \%)$, and stillbirth $2(2.8 \%)$ caesarean section $(23.3 \%)$ for various indications. 19.23\% had term PROM, 9.09\% had PPROM, 5.76\% had term IUGR, 3.84\% term IUD, preterm IUD accounts for $9.09 \%$ and still birth accounted for about $1.92 \%$ which was term, pre-eclampsia accounted for $4.76 \%$, malpresentation for $7.93 \%$, total 3 cases of antepartum hemorrhage out of which placenta previa accounts for about $3.1 \%$ and abruption for $1.58 \%$, manual removal of placenta $4.7 \%$ and low birth weight $7.6 \%$.

Conclusions: Previous history of spontaneous abortion is associated with adverse pregnancy outcome. There is increased risk of abortion, preterm delivery, need for caesarean sections and fetal loss which can be reduced by booking and giving antenatal care.
\end{abstract}

Keywords: First trimester bleeding, Pregnancy complications, Recurrent abortion

\section{INTRODUCTION}

Spontaneous pregnancy loss or miscarriage (abortion before 24 weeks of gestation) occurs in $\sim 15 \%$ of pregnancies. ${ }^{1}$ In India occurrence of spontaneous abortion in urban areas is high as compared to rural area. Risk of recurrent miscarriage (three back to back spontaneous abortions) has been reported in $0.5-3 \%$ of pregnancies and is more common in women with initial miscarriage. ${ }^{1,2}$ The definite cause for previous spontaneous abortion cannot be found in about half of cases in spite of thorough investigations. ${ }^{2}$ The main causes for recurrent abortions include anatomical disorders, hormonal abnormalities, genetic anomalies and thrombophilia. ${ }^{2}$
Previous abortion in a women increases risk of threatened abortion, preterm delivery, and fetal loss. ${ }^{3}$ These factors has to be considered when deciding for antenatal close observations and management of pregnancy in patients with history of previous spontaneous abortions. ${ }^{3}$ Studies have reported a favourable outcome with $70-80 \%$ live birth with counselling and supportive care in patients with previous abortions. ${ }^{4}$

The aetiology of spontaneous abortion is often complex and obscure. The causes of abortion can be;

- Fetal factors - aneuploidy

- Maternal factors - infections 
- Medical disorders - diabetes, thyroid dysfunction, cardiac diseases

- Radiation and chemotherapy for cancer

- Nutritional factors - extreme obesity and severe hyper emesis gravidarum

- Drug abuse and social habits - alcohol and smoking

- Immunological factors - anti-phospholipid antibody syndrome.

\section{Objective of this study were}

The present study is aimed at fulfilling the following objectives:

- To study the pregnancy outcome in a patient with history of first trimester bleeding in her previous pregnancy, which can be evaluated

- To evaluate various organic pathologies in order to prevent consequences like threatened abortion, preterm labour, pre-eclampsia.

\section{METHODS}

A total 63 pregnant women attending OPD and admitted in department of obstetrics and gynaecology, Yenepoya Medical College, from April 2017 to September 2017, considered and outcome were studied.

\section{Inclusion criteria}

- It was a prospective study of 63 pregnant women who were admitted in department of obstetrics and gynecology, Yenepoya Medical College, from April 2017 to September 2017, considered and outcome were studied.

\section{Exclusion criteria}

- Patients with induced abortion, history of spontaneous abortion with twin gestation, medical disorders like PIH, chronic hypertension, GDM, Juvenile DM, Heart disease, were excluded from the study.

\section{Statistical analysis}

A total statistical analysis was performed using the statistical packages for the social sciences version 16.0.1. A $p$ value of $<0.05$ was considered as statistically significant.

\section{RESULTS}

Table 1 describes about demographic data of the patient like age, education level, socio economic status, occupation, annual income of family. Majority of the patients belonged to age group of 21-29 years, most of them had a formal education till primary level and were home maker by occupation, lower middle class according to modified Kuppuswamy classification of socioeconomic status who had family income of less than 50,000 Rs. per annum.

Table 1: Demographic data.

\begin{tabular}{|lll|}
\hline Variable & Value & $\%$ \\
\hline Age (mean) & $21-29$ years & $57.1 \%$ \\
\hline Educational level & Primary level & $61.4 \%$ \\
\hline Socio economic status & Lower middle class & $93 \%$ \\
\hline Occupation & Home maker & $91 \%$ \\
\hline Annual income & $<50,000$ & $83 \%$ \\
\hline
\end{tabular}

Table 2 depicts number of previous abortion patient had. Majority of patients had previous 1 abortion which accounted for $45.7 \%$, previous 2 and 1 abortion were $38.6 \%$ and $15.7 \%$ respectively.

Table 2: Patients with total number of previous abortions.

\begin{tabular}{|l|ll|}
\hline $\begin{array}{l}\text { Number of previous } \\
\text { abortions }\end{array}$ & Number $(\mathbf{N}=\mathbf{6 3})$ & $\%$ \\
\hline 1 & 28 & $45.7 \%$ \\
\hline 2 & 24 & $38.6 \%$ \\
\hline 3 & 11 & $15.7 \%$ \\
\hline Total & 63 & $100 \%$ \\
\hline
\end{tabular}

Table 3: Outcome of pregnancy.

\begin{tabular}{|c|c|c|}
\hline Outcome & Number $(N=63)$ & $\%$ \\
\hline Full-term delivery & 52 & $82.5 \%$ \\
\hline Preterm delivery & 7 & $11 \%$ \\
\hline $\mathrm{I}^{\mathrm{st}}$ trimester abortion & 4 & $6.5 \%$ \\
\hline $\mathrm{II}^{\mathrm{nd}}$ trimester abortion & 0 & $0 \%$ \\
\hline
\end{tabular}

Table 4: Adverse outcome of pregnancy.

\begin{tabular}{|llll|}
\hline \multirow{2}{*}{ Adverse outcome } & Number & $\%$ \\
\hline \multirow{2}{*}{ PROM } & Term PROM & 10 & $19.23 \%$ \\
\cline { 2 - 4 } & Preterm PROM & 1 & $9.09 \%$ \\
\hline IUGR & Term IUGR & 3 & $5.76 \%$ \\
\hline \multirow{2}{*}{ IUD } & Term IUD & 2 & $3.84 \%$ \\
\cline { 2 - 4 } & Preterm IUD & 1 & $9.09 \%$ \\
\hline Still birth (term) & 1 & $1.92 \%$ \\
\hline Pre-eclampsia & 3 & $4.76 \%$ \\
\hline Mal presentation & 5 & $7.93 \%$ \\
\hline \multirow{2}{*}{$\begin{array}{l}\text { Antepartum } \\
\text { haemorrhage Placenta previa }\end{array}$} & 2 & $3.1 \%$ \\
\cline { 2 - 4 } $\begin{array}{l}\text { Placental } \\
\text { abruption }\end{array}$ & 1 & $1.58 \%$ \\
\hline \multicolumn{2}{|l}{ Manual removal of placenta } & 3 & $4.76 \%$ \\
\hline \multicolumn{2}{|l}{ Low birth weight } & 6 & $9.5 \%$ \\
\hline
\end{tabular}

Table 3 depicts outcome of pregnancy who had previous history of spontaneous abortion. Majority of patients that is $82.5 \%$ had full term delivery, only $11 \%$ of patients had preterm delivery, remaining $6.5 \%$ had abortion during first trimester. 
Table 4 shows adverse outcome of pregnancy in patients studied. 19.23\% had term PROM, 9.09\% had PPROM, $5.76 \%$ had term IUGR, 3.84\% term IUD, preterm IUD accounts for $9.09 \%$ and still birth accounted for about $1.92 \%$ which was term, pre-eclampsia accounted for $4.76 \%$, malpresentation for $7.93 \%$, total 3 cases of antepartum haemorrhage out of which placenta previa accounts for about $3.1 \%$ and abruption for $1.58 \%$, manual removal of placenta $4.7 \%$ and low birth weight $7.6 \%$.

Table 5: Mode of termination of pregnancy.

\begin{tabular}{|lll|}
\hline $\begin{array}{l}\text { Mode of termination of } \\
\text { pregnancy }\end{array}$ & Number & $\%$ \\
\hline FTND & 21 & $34 \%$ \\
\hline LSCS-emergency & 19 & $31 \%$ \\
\hline Instrumental delivery & 11 & $17.5 \%$ \\
\hline Spontaneous abortion & 4 & $6.5 \%$ \\
\hline $\begin{array}{l}\text { Abnormal labour with full term } \\
\text { IUD }\end{array}$ & 2 & $2.5 \%$ \\
\hline Abnormal labour with stillborn & 1 & $1.5 \%$ \\
\hline Abnormal labour with preterm & 4 & $6 \%$ \\
\hline $\begin{array}{l}\text { Abnormal labour with preterm } \\
\text { with IUD }\end{array}$ & 1 & $1 \%$ \\
\hline Total & 63 & $100 \%$ \\
\hline
\end{tabular}

In Table 5 it could be understood that FTND was 21 accounted for $34 \%$, LSCS-emergency was 19 with total of $31 \%$. Instrumental delivery was 11 total of $17.5 \%$, spontaneous abortion for $6.5 \%$, abnormal labour with full term IUD accounts for $2.5 \%$, abnormal labour with stillborn accounts for $1.5 \%$, abnormal labour with preterm delivery accounts for $6 \%$, abnormal labour with preterm with IUD $1 \%$.

\section{DISCUSSION}

First-trimester bleeding is not only associated with miscarriage but also with a higher rate of pregnancy complications. There is a strong association between first-trimester vaginum bleeding and adverse pregnancy outcome. The probability of abortion and adverse pregnancy outcome increases as amount and duration of bleeding increase, especially when accompanied with abdominal pain. The outcome has been analysed with respect to maternal and fetal outcome. Maternal outcomes were noted as normal full-term deliveries, preterm deliveries, premature rupture of membranes, malpresentation, antepartum hemorrhages, cesarean section, instrumental delivery, manual removal of palcenta, recurrent abortions. Fetal outcome were intrauterine growth restriction, low birth weight, admission to NICU, IUD, still birth.

In comparison with women with a previous successful pregnancy, this study data suggests that women with an initial miscarriage have an increased risk of some obstetric complications. These complications include recurrence of abortion, instrumental delivery, PROM and ectopic pregnancy. They are also more prone to preterm deliveries. These include pre-eclampsia, threatened miscarriage, antepartum hemorrhage, induced labour, instrumental delivery and manual removal of placenta, IUGR, preterm delivery, malpresentation and low birth weight.

Table 6: Comparison of the current study results with previous studies.

\begin{tabular}{|lllllll|}
\hline Results & Current study & Jivraj et $\mathbf{a l}^{6}{ }^{6}$ & Battacharya et al, $^{7}$ & Sheiner et al, $^{2}$ Agarwal et al, $^{8}$ \\
\hline FTND & 21 & - & - & - & 74.3 \\
\hline Preterm delivery & 7 & 13 & 9.2 & - & 8.6 \\
\hline Preeclmpsia & 3 & - & 4.4 & 5.1 & - \\
\hline Abortion & 4 & - & 27.1 & 9.6 & 14.3 \\
\hline Instrumental delivery & 11 & - & 26.7 & - & - \\
\hline Antepatum haemorrhage & 3 & - & 12 & 2 & - \\
\hline Malpresentation & 5 & - & 18 & - & - \\
\hline Manual removal of placenta & 3 & - & 3.9 & 15.9 & 23.3 \\
\hline Caesarean delivery & 19 & 36 & 4.2 & 9.5 & - \\
\hline Low birth weight & 6 & - & 8.5 & 2 & - \\
\hline IUGR & 3 & - & 2.6 & - & 2.8 \\
\hline Still birth & 1 & 2.5 & 1 & 1.7 & - \\
\hline IUD & 3 & 4 & 0.8 & & - \\
\hline
\end{tabular}

As shown in Table 6 Bhattacharya et al, stated that miscarriage group faced a higher risk of pre-eclampsia (4.4\%), threatened abortion $(27.1 \%)$, rate of caesarean section $(4.2 \%)$, preterm delivery $(9.2 \%)$ and low birth weight $(8.5 \%)$. Incidence of high-risk factors were also increased in the present study as described in above results. ${ }^{7}$ Taylor et al reported an increased incidence of Placenta previa in patients with a previous abortion, supporting the present study. ${ }^{9}$ Jivraj et al, in September 2000 found that rates of preterm delivery $(13 \%)$, perinatal 
loss $2.5 \%$ and caesarean section (36\%) were significantly higher than those of control group. ${ }^{6}$

\section{CONCLUSION}

Previous unfavourable pregnancy outcome increases the risk of adverse outcome in the future pregnancies. There is association between previous spontaneous abortion and PROM (19\%), IUD (3\%) in the subsequent pregnancies. There is also increase in the incidence of IUGR, still birth, recurrence of abortion and preterm delivery in the subsequent pregnancies, preceded by spontaneous abortions. As the number of previous abortions increase the incidence of successful outcome decreases. The numbers of previous abortions increase the incidence of low birth weight increases. The percentage of operative deliveries is more in the cases who had previous abortions. Previous abortions have a definite impact on the successful outcome of future pregnancies. Hence for such pregnancies, careful antenatal care is mandatory. Careful surveillance is required in pregnancies preceded by spontaneous abortions, for early detection of possible complications.

\section{ACKNOWLEDGMENTS}

Authors would like to thank our guide Dr Ramya N. R. for her constant support and encouragement.

Funding: No funding sources Conflict of interest: None declared

Ethical approval: The study was approved by the Institutional Ethics Committee

\section{REFERENCES}

1. Brigham SA, Conlon C, Farquharson RG. A longitudinal study of pregnancy outcome following idiopathic recurrent miscarriage. Hum Reprod. 1999;14(11):2868-71.
2. Sheiner E, Levy A, Katz M, Mazor M. Pregnancy outcome following recurrent spontaneous abortions. Eur J Obstet Gynecol Reprod Biol. 2005;118(1):615 .

3. Agrawal S, Khoiwal S, Jayant K, Agarwal R. Predicting adverse maternal and perinatal outcome after threatened miscarriage. Open J Obstet Gynecol. $2013 ; 2014$.

4. Clifford K, Rai R, Regan L. Future pregnancy outcome in unexplained recurrent first trimester miscarriage. Hum Reprod. 1997; 12(2):387-9.

5. Horsager R, Roberts S, Rogers V, Santiago-Muñoz P, Worley K, Hoffman B. Williams obstetrics, $24^{\text {th }}$ Edition, Study Guide. 24 $4^{\text {th }}$ edition. New York: McGraw Hill Education; 2014:448.

6. Jivraj S, Anstie B, Cheong YC, Fairlie FM, Laird $\mathrm{SM}, \mathrm{Li}$ TC. Obstetric and neonatal outcome in women with a history of recurrent miscarriage: a cohort study. Hum Reprod. 2001;16(1):102-6.

7. Bhattacharya S, Townend J, Shetty A, Campbell D, Bhattacharya S. Does miscarriage in an initial pregnancy lead to adverse obstetric and perinatal outcomes in the next continuing pregnancy? BJOG Int J Obstet Gynaecol. 2008;115(13):1623-9.

8. Agrawal S, Agrawal V, Suhane R. Pregnancy outcome following spontaneous abortions. Int $\mathrm{J}$ Reprod Contracept Obstet Gynecol. 2015;4(6):18913.

9. Taylor VM, Peacock S, Kramer MD, Vaughan TL. Increased risk of placenta previa among women of asian origin. Obstet Gynecol. 1995;86(5):805-8.

Cite this article as: Faswila M, Ramya NR. Pregnancy outcome in patient who had first trimester bleeding in previous pregnancy: a prospective study. Int J Reprod Contracept Obstet Gynecol 2020;9:1559-62. 